\title{
Dynamic Behavior of Materials
}

\section{Proceedings of the Symposium Held during Materials Week October 2-6, 1994 \\ Rosemont, Illinois \\ Part I}

\section{Foreword}

The field of "dynamic behavior of materials" encompasses a wide array of phenomena and effects of important technological consequences: high-strain-rate deformation, adiabatic shear localization, shockwave effects, dynamic fracture and fragmentation, dynamic consolidation of materials, shock synthesis and shock-induced chemical reactions, dynamic response of composite materials, and impact. In addition to the traditional military applications in the areas of weapons, armor, and armor defeat, increasing emphasis is being placed on civilian aerospace and manufacturing applications, such as foreign object damage, high-speed machining, crash worthiness, micrometerite impact, new materials synthesis, etc.

The growing recognition that there was a need to expose the materials community to the diverse aspects of the dynamic behavior of materials led to the organization of this symposium; it was cosponsored by the ASM/MSD Flow and Fracture Committee and the TMS Mechanical Metallurgy Committee. It consisted of six sessions, which were very well attended. The resulting papers are being published by Metallurgical and Materials Transactions in two parts, after being reviewed by the same exacting standards as regular papers.

These proceedings represent significant original contributions and the organizers/editors hope that future symposia in the same field will be held.

G. T. Gray III Los Alamos National Laboratory

M. A. Meyers University of California, San Diego

N. N. Thadhani Georgia Institute of Technology 